THE ALEZA LAKE FOREST EXPERIMENT STATION:

\title{
ITS DEVETOPMENT AND PURPOSE
}

\author{
P. M. Barr, \\ Research Division, \\ British Columbia Forest Service.
}

The Experiment Station of the British Columbia Forest Service at Aleza lake is a comparatively new institution, dating only from 1924, but sinde that time considerable work has been accomplished, and plans have been developed for a somewhat comprehensive programme in the future. It may be of interest at this time to review briefly the objectives and work of the Station and to consider some of the main features of the investigative work already under way.

About 1922 it became apparent that extensive industrial development was about to take place in the spruce forests of Central British Columbia, particularly in the valley of the Upper Fraser River. Earlier woods operations had indicated that with prevailing methods of cutting the conditions of regeneration following logging were extremely unsatisfactory, a scattered stand of small balsam being left as advance growth from the original stand, and no new reproduction taking place.

Over most of the region the mature stand consists of about oqual numbers of spruce and balsam, the former of larger size, and forming about $75 \%$ of the gross cubic volume. The balsam, however, is badly infected with heart rot, and is so defective that in log.ging practically none of it is cut. As a result, most of the seedbearing trees left after cutting are balsam, causing new regeneration as well as the advance growth to be almost entirely balsam.

The situation is similar, in many respects, to that existing in spruce forests of eastern Canada, but with the difficulties accentuated by the extent to which defect is present in the balsam.

While a considerable body of experience had been built up in the management of spruce forests in Eastern North America, it was apparent that the problem had not been solved entirely. Even for the information already available, further work was still necessary, to determine if it was applicable to western forests, with dissimilar conditions of climate, soil, and topography, and different species of trees. The Forest Service therefore decided to develop an investigative organization in the Interior of the Province for the purpose of making a careful study of the spruce problem. 
The main objective, of $\operatorname{course}$, was the development of a cutting method which would insure an adequate second growth of desirable species on cutover spruce lands, but it was realized that an ideal method, even if developed, would have to be adjusted to meet prevailing economic conditions.

At the beginning, it was felt that it would be advisable to have a centrally located forest for investigative work where, as far as possible, the research studies could be carried on, and their results put into practice in an experimental way. Experience has completely demonstrated the wisdom of this plan. The men engaged on research work have been able to devote their full time to their investigations, supervision has been facilitated, and loss of time and expense due to travelling has been reduced to a minimum. Members of the Station staff tho are working on different problems, haye

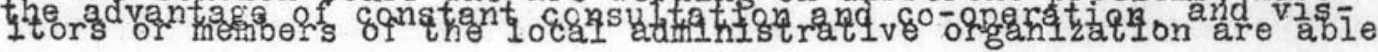
to see all phases of the work with a minimum of time and travel.

The place selected for the experimental work was a forest of 6500 acres, situated south of the Fraser River, 34 miles east of Prince George. This area forms the main portion of the watershed of a small creek about seven miles in length, and constitutes a natural logging and silvicultural unit. With the exception of 200 acres of logged of $f$ land, and numerous small open swamps, the whole block is well timbered with a fairly uniform stand of spruce and balsam, from 125 to 200 years old, and averaging about 16,000 board feet to the acre. The surface has a general slope to the northwest, and is fairly regular, the prevailing rolling surface being broken occasionally by small narrow valleys tributary to the main stream which drains the forest. The climate is characterized by dry summers and by long winters with heavy snowfall, but irregular temperatures, periods of extremely cold weather alternating with thaws or moderate frosts. The total annual precipitation is in the neighborhood of 25 inches.

The forest is advantageously situated to permit of the utilization of timber produced in experimental cuttings. The main stream referred to empties into Aleza Lake within one mile of the Northern boundary of the forest and on this lake there are two sawmills dependent on local logging operations for their timber supply. The Canadian Mational Railway passes along the north side of the forest, and makes possible the convenient shipment of logs to other nearby mills. The Station is also served by the main highway which is being projected up the Fraser valley east of Prince George. Most of the local population are loggers or small farmers accustomed to winter work in the woods and a regular labor supply is insured in this way.

Shortly after the experimental forest was set aside, it was carefully mapped and cruised, and a centrally located site selected 
for headquarters buildings. On this site there have been erected a main staff building which inoludes an office and laboratory in addition to living quarters for ten men, a dining hall, and a residence for the officer in charge. Stables and workshops have yet to be built. A road has been built to connect this headquarters site with the public road already referred to; about 15 miles of trail have been cut out to render all parts of the forest conveniently accessible, and about one mile of logging road has been built in connection with the experimental cuttings. For purposes of fire detection, a lookout tower 70 feet high has been erected on a knoll near the station buildings.

The principal investigation has been a study of the factors controlling the natural establishment of spruce seedlings in a mature stand, carried out by means of a series of twelve permanent plots laid out in 1925 and 26 , and examined regularly since that time. Each plot is two chains square, divided into four equal parts on each of which a quadrat of $1 / 200$ acre has been selected for intensive study. These quadrats have been arranged as follows:-

Number 1. Left untreated, as a control.

". 2. Trenched, to remove root competition.

" 3. Humus romoved, to expose mineral soil.

" 4. A combination of conditions (2) and (3).

For seedling establishment, natural seedfall has been relied upon, and the progress of germination and survival has been followed by means of examinations, repeated several times each season, during which each new seedling is marked with a numbered label and recorded in order.

The twelve plots are carefully distributed over the forest to include an adequate variety of sites, exposures and densities of overwood; during 1928 the series was increased to sixteen, to further improve the conditions of distribution.

During the first growing season following the establishment of the twelve plots described above, it was seen that a remarkable growth of tree seedlings and herbaceous vegetation was taking place on certain of the quadrats, particularly those which had been trenched, and those on which the mineral soil had been exposed. A second series of two plots, each with eight small quadrats $1 / 1000$ acre in area, was prepared for the purpose of observing the trend of soil moisture throughout a growing season, and the effect of the moisture conditions on spruce seedlings. These two plots were later supplemented by two others. 
In addition to this main silvical study, a considerable number of other plots were established for various purposes. Four of these, laid down in 1926, were devoted to the subject of the rate of growth of trees remaining after logging. Six others were examined in connection with a study of the cause and extent of decay in balsam in the experimental forest. An additional six were established for experiments in brush disposal. One of the members of the staff of the station has also spent a season in studying the growth and yield of the mixed, and irregular-aged stand, as part of the general programme of yield studies which is being carried on by the Research Division throughout the Province.

It is not possible in the compass of this brief article to discuss in any detail the results of the investigations briefly referred to in the above. The main investigation, with its 16 plots and 64 quadrats, requiring several hundred examinations during the past three years, is probably one of the most comprehensive studies of the silvical factors controlling spruce reproduction that has yet been undertaken, and considerable field work is still necessary before the results of this project can be suitably presented in published form. However, it is hoped that this will be possible within the next few years.

In addition to using the Aleza Lake forest as a center for investigative work, it is proposed to develop it as a demonstration area for forest management work, administering it on a basis of sustained yield with regular annual cuttings. The preliminary regulation studies which have been made indicate that it will be desirable, until better information can be secured, to have an annual cut of from $1,000,000$ to $1,300,000$ board feet, on an area of from 65 to 80 acres. Such an area each year will, of course, provide ample scope for experimental work in silviculture, and it is proposed to make the fullest possible use of this opportunity, not only in trying out various cutting methods, but by undertaking brush disposal work, studies of logging cost, and where possible improvements in logging practice and utilization.

It is believed that the development of such a demonstration area will be advantageous in more ways than one. Primarily, it will enable the investigative staff to put the results of their research work into practice and to test their theories in actual logging operations. As new details of silviculture practice, based on experiment, are tested and found practicable, they can be applied on a larger scale in the Crown forests of the surrounding region.

Secondarily, the development of an area under regulation will furnish a model for the local administrative staff who will be faced in the near future with the problem of working out management plans for the publicly owned forests under their supervision. Finally, it is hoped that the example of a managed, producing, sustained forest which the Aleza Lake area will furnish will be of considerable import- 
tance in influencing local private owners of timberlands, particularly the larger operators, to bring their own holdings under management for permanent production, and to practice improved utilization and methods of brush disposal.

The first experimental cutting on the Station forest was undertaken in the winter of 1926-27, 1,066,200 board feet of spruce and balsam being cut from an area of 79 acres. While both spruce and balsam were cut to the lowest merchantable diameter, local economic conditions did not permit of the removal of trees below 12 inches in diameter, and the operation was therefore in effect cutting to a diameter limit. For subsequent seed supply, reliance was placed upon marginal timber and the numerous residual trees. Experimental work connected with the cutting consisted of a study of the cost and effect of five methods of brush disposal, carried out on 1-acre plots.

Interruptions in the work of the personnel of the Station, together with the shutting down of the local sawmill made it advisable to reduce the sise of the 1927-28 cutting area, and to entirely abandon the cutting planned for 1928-29. In the former year, 200,000 f.b.m. were cut on an area of 12 acres. Diameter limit cutting was again practised, with brush disposal by live burning, and the advance growth provided part of the reproduction aupplemented with regeneration from the marginal timber and the seed trees left by the diameter limit system. Experimental work consisted of the establishment of a number of plots and transects on which mineral soil was exposed, for the purpose of studying reproduction on this type of seedbed in cutover areas.

It is expected that in 1929-30 and subsequent years it will be possible to maintain the regular annual cut of $1000-1300 \mathrm{M}$. stipulated by the management plan.

While it has been possible to carry on practically all the research work of an intensive or basic nature at the Experiment Station itself, certain studies have had to be conducted in other parts of the Upper Fraser region. These have been, for the most part, general examinations rather than actual experimental work. In 1924 a general survey of the composition and density of advance reproduction was made throughout the region. This work was confined to green timber, and in 1926 a somewhat similar survey was carried out in burned over areas. Measurements for volume and yield tables also have been taken in other parts of the district, but the Experimental Forest is so centrally located that it has been possible to undertake all these activities as extensions of the station work, requiring a minimum of supervision, and obviating any duplication of organization and expense.

Since the inception of the work at the Experiment Station, the same men have carried on the work from year to year, as far as 
possible, although during the winter the investigators return to the head office. This constant and continuous association with the work in the field has been of great benefit in forming a clear conception of the essential details of the main problem of spruce silviculture. The experience already gained has shown that the forest at Aleza Lake presents practically unlimited opportunity for valuable forestinvestigative work, particularly in the fields of silviculture, soil science, and forest ecology, and in the important question of forest growth and yield. With the passing of the years, and the replacement of the present somewhat uniform stand by a succession of age classes produced by various cutting methods, the opportunities for diversified work will increase.

In the preceding paragraphs it has not been possible only to outline the work of the Experiment Station at Aleza Lake. As the various projects now under way are completed their results will be made available, and it is hoped that the benefits of the Station will not be confined to the local area in which it is situated. The regeneration of cutover spruce lands undoubtedly constitutes the most important question at present facing those concerned with the management of Canadian forests, and in its principal aspects the problem is common to the whole Dominion. In this matter the most general. benefit may be obtained by constant and intimate cooperation between all those agencies which are concerned. In addition to securing the information necessary to solve local problems, it is also the aim of the Aleza lake Experiment Station to participate as far as possible in this common effort. 